\title{
On the processing of simple visual and auditory stimuli at distinct levels*
}

\author{
DAVID LaBERGE $\dagger$ \\ University of Minnesota, Minneapolis, Minnesota 55455
}

Two RT studies explored the possibility that identification of a single stimulus can take place through more than one perceptual route. In the first experiment, mean RT to color was systematically changed by varying type of catch stimulus. In the second experiment, the form of the RT distribution to a tone was changed by varying type of catch stimulus. Considerations of distribution means and shapes led to the conclusion that detection and discrimination are two of the alternative levels of perceptual processing which can be evoked in rapid identification of these stimuli.

Recent investigations have been directed toward identifying the kinds of operations which may be performed on the information arriving from receptor surfaces. Treisman (1969) has drawn on a wide range of studies to propose a general system of sensory analyzers which test a stimulus input for such features as spatial location, color, size, and speech. Sternberg has proposed perceptual models consisting of chains of stages, and has studied properties of these stages using reaction-time measures within subtractive designs (Sternberg, 1966) and more recently with additive designs (Sternberg, 1969). Posner and Mitchell (1967) employed a "same-different" matching task in an attempt to control the level or "node" at which letters were processed. Their Ss were instructed to identify two letters by their physical identity (e.g., AA), name identity (e.g., Aa), or rule identity (e.g., both vowels). They found that the three instruction conditions produced different mean latencies, and this result led them to conclude that there existed separate levels in the processing of letter stimuli.

While most studies to date have dealt with identification of stimulus patterns such as letters, lines, and speech forms, the present experiments treat simple colors and tones, and explore the possibility that separate levels can be isolated in their processing.

The design of the present experiments is based on the subtractive method of Donders (1868), but it employs only his c technique, in which the $S$ responds with a buttonpress to the target stimulus and withholds his response to a "catch" stimulus. Throughout each experiment the

\footnotetext{
*This research was supported jy Public llealth Service Research Grant MH 16270-02 and the Center for Research in Human Learning (National Science Foundation Grant GS-541). The author thanks Mary Tupa and David Feigal. who conducted the experiments.

tAddress: Elliott Hall, University of Minncsota. Minneapolis, Minnesota 55455.
}

farget stimulus remains the same, while the catch stimulus is varied from condition to condition in an attempt to control the levels at which the stimulus is processed. Classical objections to the subtractive method (cf. Woodworth, 1938) have centered around the fact that comparisons of latency data under $a, b$, and $c$ methods falsely assume that other factors affecting reaction time are constant across the methods. In particular, Woodworth noted that the a reaction (without catch trials) involved greater motor readiness than the $b$ or c reactions, and therefore straightforward subtraction of mean RTs of pairs of these tasks suffered from a confounding due to changes in preparatory set. In the case of the present designs, however, the comparisons of latency data are made entirely within the c technique, using the same stimulus and response throughout, while maintaining a constant percentage of catch stimulus trials. Thus there would appear to be much less reason here to suspect changes in either response bias or stimulus bias as the type of catch trial is varied across conditions.

Although the basic design could have been executed with a two-button, two-stimulus assignment, perhaps with a "same-different" instruction, it was felt that more stable latencies would be obtained with the increased control over perceptual and response biases produced by the single response method. When there is only one response, there is less possibility of fluctuations in response bias, compared to the two-response design where $S$ 's expectancies may induce him to vary his bias from trial to trial in ways not directly controlled by the $\mathbf{E}$ (LaBergc, legrand, \& Hobbic, 1969). Similarly, when a particular stimulus occurs a large proportion of the time, the $S$ can casily be instructed to bias his attention toward that stimulus virtually all of the time (LaBerge, Van Gelder, \& Yellot1, 1970), in contrast to designs where $S$ is lelt free to form his own trial-by-trial expectations as to what stimulus will occur. Thus the experiments to be reported here were initiated with reasonable assurance that repeated presentations of the same stimulus were delivered to a $S$ who was in a relatively constant attention state with respect to both response and stimulus biases.

\section{Method}

\section{EXPERIMENT 1}

All responses in this experiment were made by pressing a single button with the right-hand fingers. The button was circular $(2.5 \mathrm{~cm}$ in diam) and required $80 \mathrm{~g}$ of force to travel a vertical distance of $3 \mathrm{~mm}$. The $S$ was instructed to press the button only when a green or an orange square appeared in the aperture in front of him. He was instructed not to respond to the presentation of "catch" stimuli, namely a yellow, blue, or red square, an arabic numeral " 2 ," a 1,000-Hz tone, or a blank (nothing). The visual stimuli were produced by an IEE Series 10 readout, which presented a luminous square of color, $3 \times 3 \mathrm{~cm}$ at $5 \mathrm{fL}$, with a rise time of approximately $25 \mathrm{msec}$. Tones were produced by a Grason-Stadler oscillator and presented to the $S$ binaurally through earphones. Each presentation of a stimulus was preceded by a cue, either a green or an orange square, indicating to the $S$ what stimulus was most likely to occur on that trial. Each block contained 40 trials; half of these were green-cue trials, half orange-cue trials, presented randomly. On the trials when a green cue occurred, a green stimulus followed on 14 trials and a catch trial stimulus followed on 6 trials. Similarly, on the trials when an orange cue occurred, an orange stimulus followed on 14 trials and a catch stimulus followed on 6 trials

Only one type of catch trial was given within each series of three blocks. For example, in one series the green- and orange-cue trials incorporated a $1,000-\mathrm{Hz}$ tone for all catch trials, and on another series, the color red for all catch trials. For a special condition in which the catch-trial stimulus was intended to be very similar to the target stimulus, a blue catch stimulus was paired with the green stimulus and a yellow stimulus was paired with the orange stimulus.

The five Ss were volunteers from introductory psychology classes. They were instructed concerning the function of the cue event and were given practice trials until their latencies stabilized and their error rates were below $8 \%$. Then each $\mathbf{S}$ was given the five catch stimulus conditions in sequence. A Latin-square design prescribed the orders in which the five $S s$ received the five different catch-trial conditions.

The events of a trial were as follows: An orange or green cue was presented for 




Fig. 1. Mean latency as a function of catch condition.

$1,000 \mathrm{msec}$, followed by a blank for $1,600 \mathrm{msec}$, and then the stimulus occurred. The onset of the response terminated the stimulus. When the response latency was less than $350 \mathrm{msec}$, the letter " $A$ " appeared for $50 \mathrm{msec}$, followed by a 350 -msec blank before the cue of the next trial appeared. When the response latency was greater than $350 \mathrm{msec}$, no feedback was given. When a catch stimulus was presented, a timer automatically turned off the stimulus after $350 \mathrm{msec}$. On the occasions where $S$ pressed the button to a catch stimulus, he received a $50-\mathrm{msec}$ burst of white noise in the headphones.

All presentation and recording events were controlled by a CDC 160 computer. The Ss were instructed to accumulate as many " $A$ " feedback events as they could without errors. Following every block of trials, $S$ was shown the electric counter which displayed the number of " $A$ " events he had achieved on that block.

\section{Results}

Figure 1 shows the mean latencies to orange and green stimuli as a function of the type of catch-trial stimulus employed. There is an apparent increase in mean latency as one moves from left to right across the graph. A simple overall test of this increase is provided by a Friedman two-way analysis of variance by ranks (Siegel, 1956). For each $S$ the mean latencies to orange and green stimuli over the last two blocks of each condition were combined. These combined means were then ranked across catch stimulus conditions. Analysis of the five sets of ranks given by the five $S s$ yielded a $\chi^{2}(4)=17.9$, which is significant beyond the .01 level.

Means for green and orange stimuli are quite similar within each of the catch stimulus conditions, except for the near condition, where the latency to orange (with a yellow catch trial) is much longer than the latency to green (with a blue catch trial).

Pairwise comparisons of mean latencies over the last two blocks of adjacent conditions reveals clear differences everywhere except for the nothing and tone comparison. Although the mean latency over the last two blocks under the tone condition is greater than that of the nothing condition for four out of five of the Ss, the difference is too small to engender confidence that a true difference exists here.

Error percentages and latencies across the last two blocks of each condition are shown in Table 1. Apparently, when the catch stimulus conditions produced faster responding, they did not at the same time produce a greater percentage of errors. In fact, the opposite effect appears to be the case.

\section{EXPERIMENT 2}

The results from Experiment 1 indicate that changing the type of catch stimulus paired with a constant color stimulus systematically changes the mean latency of a response to the color stimulus. To attempt a provisional characterization of the perceptual processes which are
Table 1

\begin{tabular}{lccc}
$\begin{array}{ccc}\text { Catch } \\
\text { Conditions }\end{array}$ & $\begin{array}{c}\text { Mean } \\
\text { Correct } \\
\text { Latency }\end{array}$ & $\begin{array}{c}\text { Mean } \\
\text { Error } \\
\text { Latency }\end{array}$ & $\begin{array}{c}\text { Percent } \\
\text { Error }\end{array}$ \\
\hline Nothing & 265 & 227 & 1.1 \\
Tone & 272 & 253 & 5.5 \\
Digit & 303 & 239 & 8.3 \\
Far Color & 346 & 272 & 7.7 \\
Near Color & 432 & 342 & 8.3 \\
\hline
\end{tabular}

produced by the catch stimulus conditions, one would like to have information about higher moments of the distributions, preferably a plot of the distributions themselves.

To obtain orderly distribution plots, it is very helpful to maintain virtually steady-state responding on the part of the Ss. The five Ss used in Experiment 1 had no more than 1 day's training before testing. Therefore, a second experiment was planned with highly trained $\mathrm{Ss}$ and with measures of performance stability to determine acceptability of data for plotting distributions.

To generalize the pattern of findings to another modality, the second experiment was performed with a tone as a target stimulus.

\section{Method}

Three paid Ss were run in $1 / 2$. to $3 / 4-h$ sessions 2 days a week for 12 weeks. The stimulus to which they were to respond by pressing a button was always a $1,000-\mathrm{Hz}$ tone at a level of $80 \mathrm{~dB}$ SPL. The catch-trial stimuli employed were a $1,200-\mathrm{Hz}$ tone, white noise, a red square, and nothing.

Each block of trials contained 27 target stimuli and 13 catch stimuli. Only one type of catch trial was used within any given session. The Ss were given either one or two catch-trial sessions per day, depending upon the rate at which they stabilized on a given condition. The order of presentation of catch conditions was randomized over the 24 days. Data were taken from the last 8 days.

The events of trial were as follows: A $1,000-\mathrm{Hz}$ tone cue was presented for $1,000 \mathrm{msec}$ followed by a blank for $1,000 \mathrm{msec}$, and then the stimulus was presented. When the response latency was less than a predetermined criterion, the numeral " 1 " appeared for $50 \mathrm{insec}$. When the response was greater than the criterion, a "C" appeared. The feedback was followed by a 950 -msec blank. The latency criterion used was the mean latency of the previous block of trials. This information was typed into the computer before each block. Before the next trial began a green square flashed for $50 \mathrm{msec}$ to provide a marker between trials. Catch-trial stimuli remained on for $1,000 \mathrm{msec}$ unless 
Table 2

\begin{tabular}{|c|c|c|c|c|c|c|c|c|c|}
\hline \multirow[b]{2}{*}{$\begin{array}{c}\text { Catch } \\
\text { Condi- } \\
\text { tion } \\
\end{array}$} & \multicolumn{3}{|c|}{ S AK } & \multicolumn{3}{|c|}{ S JI } & \multicolumn{3}{|c|}{ S LR } \\
\hline & $\begin{array}{c}\text { Mean } \\
\text { Correct } \\
\text { Latency }\end{array}$ & $\begin{array}{c}\text { Mean } \\
\text { Error } \\
\text { Latency }\end{array}$ & $\begin{array}{c}\text { Percent } \\
\text { Error }\end{array}$ & $\begin{array}{c}\text { Mean } \\
\text { Correct } \\
\text { Latency }\end{array}$ & $\begin{array}{c}\text { Mean } \\
\text { Error } \\
\text { Latency }\end{array}$ & $\begin{array}{c}\text { Percent } \\
\text { Error }\end{array}$ & $\begin{array}{c}\text { Mean } \\
\text { Correct } \\
\text { Latency }\end{array}$ & $\begin{array}{c}\text { Mean } \\
\text { Error } \\
\text { Latency }\end{array}$ & $\begin{array}{c}\text { Percent } \\
\text { Error }\end{array}$ \\
\hline Nothing & 201 & 276 & 2.0 & 219 & 199 & 1.2 & 206 & 244 & 6.2 \\
\hline Red & 218 & 174 & 1.2 & 228 & - & 0.0 & 204 & 185 & 6.2 \\
\hline Noise & 246 & 222 & 5.0 & 230 & 177 & 11.5 & 224 & 195 & 14.1 \\
\hline Tone & 258 & 245 & 8.9 & 266 & 261 & 7.8 & 238 & 214 & 15.2 \\
\hline
\end{tabular}

terminated by an incorrect response.

The presentation and recording events were controlled by a CDC 160 computer. The Ss were instructed to score as many "1" events as they could without error. Following each block of trials, they were shown the counter which displayed the number of "l" events achieved.

\section{Results}

Since it was intended that the data in this experiment be obtained under $S$ conditions which approached a steady state, only those blocks were selected which met specific criteria. First of all, latencies were separated according to ordinal number of trials since last catch trial for each $S$. The means of these groups of latencies could not deviate from each other by more than $20 \mathrm{msec}$ to be accepted in plotting a distribution. Similarly, block means were examined for systematic drift due to serial effects of fatigue or practice. The acceptance criterion was that the group of block means could not deviate from each other by more than $20 \mathrm{msec}$.

An additional analysis of the data was

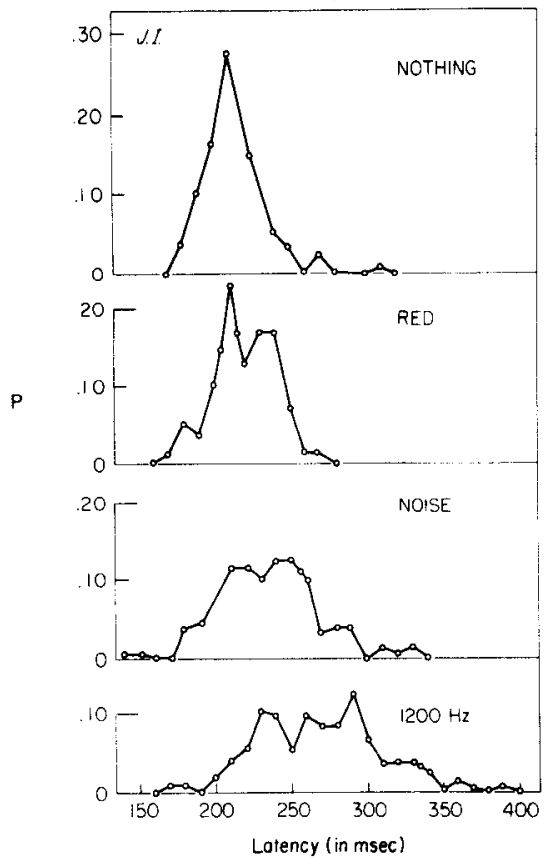

aimed at revealing a possible effect of feedback on subsequent response latencies. All trials were categorized as yielding response latencies either above or below the time "deadline" that had been typed into the computer at the beginning of that block. The question was whether a latency on Trial $n$ that was below criterion (and thus rewarded) was more likely to be followed by a latency on Trial $n+1$ that was also below the criterion. Frequency tables constructed for each $S$ showed no indication of departure from independence of latency from Trial $n$ to Trial $n+1$. Therefore, it was concluded that reward (feedback) events, as presented in this experiment, did not produce noticeable sequential effects. Error percentages and mean latencies are shown in Table 2.

The number of blocks of trials over the last 8 days of the experiment surviving the acceptance criteria for steady-state responding unfortunately was not the same for all $\mathrm{Ss}$ and all catch conditions. The number of observations in each of the distributions of Figs. 2, 3, and 4 was 162, except for J.I.'s red condition, which had

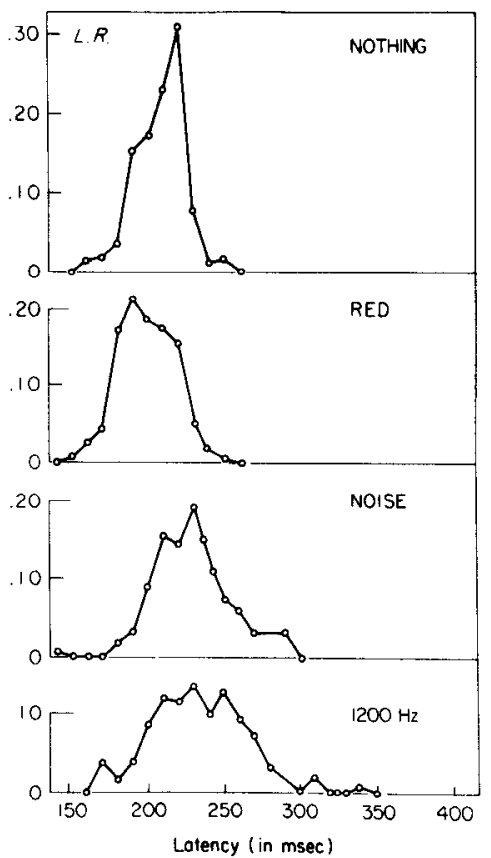

only 81 observations. Response times were grouped in cells of $10-\mathrm{msec}$ width. The means of these distributions clearly increase as one goes from the red catch stimulus to the 1,200-Hz-tone catch stimulus. However, there is some doubt that any difference at all exists between the nothing and red catch stimulus conditions. The variances of the distributions also clearly increase as one goes from the nothing condition to the tone catch stimulus condition. This is true even for S L.R., who shows a slightly smaller mean latency under the red condition as compared to the nothing condition.

Visual inspection of the distribution shapes reveals that distributions are highly peaked under the nothing condition, and become less peaked as the catch trial conditions move from red through noise to tone. Furthermore, the distributions generally appear symmetrical under nothing and red conditions, and show noticeable skewness under the noise and tone conditions.

Figs. 2, 3, and 4. Distributions of latencies for each of four catch conditions for individual Ss. 


\section{DISCUSSION}

The results of both the visual and the auditory experiments indicate that RT changes with the type of catch trial employed. The latency data order the catch stimulus conditions so as to suggest an array or hierarchy of processing mechanisms or levels, which may be called upon to analyze different types of information contained in the stimulus, even when the stimulus is as simple as a colored light or a pure tone. Given a particular stimulus input, therefore, there would seem to exist a set of alternative perceptual outputs to the response, where the choice of a particular output is controlled by the type of catch trial used.

Apparently the simplest type of distribution shown in Figs. 2, 3, and 4 is generated by the nothing catch stimulus. The almost symmetrical form of this highly peaked distribution is very similar to that obtained by Snodgrass et al (1967) in simple time-estimation tasks. They showed that this type of a distribution can be fitted better by the double monomial than by a displaced gamma distribution. However, the more complex-looking distributions produced by noise and tone catch trials depart from symmetry and high peaks and are more similar to those obtained in choice RT tasks of Snodgrass et al (1967) and of Hohle (1967). These types of low-peaked skewed distributions are fitted variously by the displaced gamma distribution (McGill \& Gibbon, 1965; Snodgrass et al, 1967), normal plus exponential (Hohle, 1967), and by a negative binomial (LaBerge, 1962).

It could be conjectured that the nothing and red catch conditions share a detection mechanism but do not produce identical distributions in these experiments because the red condition occasionally induces tone processing at higher discrimination levels, with the result that longer latencies are mixed with detection latencies. However, if by further experimental refinement it can be shown that the distributions arise from separate levels, then one could consider seriously the possibility that detection involves more than one mechanism, namely one for a particular modality and another for any event regardless of modality. If only one mechanism is involved, then the process of detection is equivalent to identifying the sensory channel the stinulus information enters.

Part of the problem of identifying distinctive levels is the possibility that a given level may have more than one state and thus generate more than one distribution. For example, the discrimination of color in Experiment 1 led to distinctly different mean latencies as a function of similarity of target to catch stimulus. The green vs blue discrimination was faster than the orange vs yellow discrimination, and the red catch condition was faster than either of these. One would be inclined to assume different states of the same discrimination mechanism rather than postulate separate levels to account for these differences since continuous experimental variation of color similarity would otherwise force the assumption of a very large number of separate mechanisms. Changes of color similarity can be represented in a model by rather simple parametric variations, such as the number of elements processed to some criterion (Audley, 1960; LaBerge, 1962) or an adjustable filter (Greenberg, 1969) leading to a family of distributions of the sort observed under the noise and $1,200-\mathrm{Hz}$ catch conditions of Figs. 2, 3, and 4. Changes from discrimination to detection, on the other hand, seem to reflect changes in the form or family of distributions because of the differences in symmetry and peakedness.

It is quite probable that the response times in the present experiments do not include a memory search component. Before the presentation of the stimulus on each trial, the $S$ was given a cue which brought the expected stimulus item out of storage and into a state of high availability. The cue was presented sufficiently in advance of the stimulus so that $S$ could activate a representation of the expected target stimulus in preparation for matching with the stimulus. If the target stimulus did in fact appear on that trial, no search was necessary and the matching time was minimal; if the catch stimulus appeared instead, then S simply did not respond. If we had supplied a second button for him to register a classification of "different," then presumably there would be a time component in his latency for this response representing the shift from the activated target representation to the catch stimulus representation. For tasks in which there are multiple catch stimuli, the "different" response latency may contain a component representing search through the stored array of alternative catch stimuli.

The levels approach to the perception of such simple stimuli as colors and tones given in the present paper suggests that the term "perceive" consists of several distinct operations, any one of which may obtain on a presentation of the same stimulus.
One can "perceive" a 1,000-Hz tone quite specifically in a narrow band of frequencies, or less clearly in a wide band of frequencies, or simply as a tone opposed to noise, or as an auditory event, and perhaps even as a nonspecific sensory event. Furthermore, it seems that several different "perceptions" may occur on one trial from one stimulus input. For example, on a given trial, $S$ may be using an early perceptual analyzer output for a speeded response, yet he can notice the outputs from other later analyzers and store these without responding to them at the time.

\section{REFERENCES}

AUDLEY, R. J. A stochastic model for individual choice behavior. Psychological Review, 1960, 67, 1-15.

DONDERS, F. C. Over de snelheid van psychische processen. Onderzoekingen gedaan in het Physiologisch Laboratorium der Utrechtsche Hooge School, 1868-1869, Tweede reeks, II, 92-120. Translated by W. G. Koster, in Attention and performance II. Acta Psychologiea, 1969, 30, 412431.

GREENBERG, G. Z. Frequency-selective detection at three signal amplitudes. Perception \& Psychophysics, 1969, 6, 297-301.

HOHLE, R. H. Component process latencies in reaction times of children and adults. In $\mathbf{L}$. $P$. Lipsett and C. C. Spiker (Eds.), Advances in child development and behavior. New York: Academic Press, 1967. Pp. 225-261.

LaBERGE, D. A recruitment theory of simple behavior. Psychometrika, 1962, 27, 375-396.

LaBERGE, D., LEGRAND, R. \& HOBBIE, R. K. Functional identification of perceptual and response biases in choice reaction time. Journal of Experimental Psychology, 1969, 79, 295-299.

LABERGE, D., VAN GELDER, P., \& YELLOTT, J. A cueing technique in choice reaction time. Perception \& Psychophysics, 1970, 7, 57-62.

McGILL, W. J., \& GIBBON, J. The general-gamma distribution and reaction times. Journal of Mathematical Psychology, 1965, 2 , $1-18$.

POSNER, M. 1., \& MITCHELL, R. F. Chronometric analysis of classification. Psychological Review, 1967, 74, 392-409.

SIEGEL, S. Nonparametric statistics. New York: McGraw-Hill, 1956.

SNO DGRASS, J. G., LUCE, R. D., \& GALANTER, E. Some experiments un simple and choice reaction time. Journal of Experimental Psychology, 1967, 75, 1-17.

STERNBERG, S. High-speed scanning in human Inemory. Science, 1966, 153, 652-654.

STERNBERG, S. The discovery of processing stages: Extensions of Donder's method. In W. G. Koster (Ed.), Attention and performance II. Acta Psychologiea, 1969, 30, 276-315.

TREISMAN, A. M. Strategies and models of selective attention. Psychological Review, $1969,76,282-299$.

WOODWORTH, R. S. Experimental psychology. New York: Holt, 1938.

(Accepted for publication October 1, 1970.) 